\title{
Solid-state Photochemical [2+2] Cycloaddition Reaction of Hydrogen-Bonded Zn(II) Metal Complex Containing Several Parallel $\mathrm{C}=\mathrm{C}$ Bonds
}

\author{
ABDUL MALIK P PEEDIKAKKAL D \\ Department of Chemistry, King Fahd University of Petroleum \& Minerals, Dhahran 31261, Saudi Arabia \\ Email: abdulmalik@kfupm.edu.sa
}

MS received 13 October 2016; revised 5 December 2016; accepted 11 December 2016

\begin{abstract}
A 2D hydrogen-bonded dinuclear $\mathrm{Zn}(\mathrm{II})$ complex, $\left[\left\{\mathrm{Zn}\left(\mathrm{H}_{2} \mathrm{O}\right)_{3}(\mathrm{bpe})_{2}\right\}_{2}\right.$ (bpe) $]\left(\mathrm{NO}_{3}\right)_{4} \cdot 3 \mathrm{bpe} \cdot 14 \mathrm{H}_{2} \mathrm{O}$, 1 (bpe $=4,4^{\prime}$-bipyridylethylene) containing coordination complex cations, $\left[\left\{\mathrm{Zn}\left(\mathrm{H}_{2} \mathrm{O}\right)_{3}(\text { bpe })_{2}\right\}_{2}(\mu \text {-bpe })\right]^{4+}$ and free bpe and lattice water molecules shows face-to-face, $\pi \cdots \pi$ stacking of two of the four free bpe molecules with coordinated bpe ligands. Out of eight bpe molecules, six are aligned in parallel fashion with short C . . C distances of 3.663-3.814 $\AA$ and they undergo photochemical [2+2] cycloaddition reaction. The photoreaction conducted on ground sample of $\mathbf{1}$ in the solid-state affords $r c t t$-tetrakis(4-pyridyl)cyclobutane (rctt-tpcb) product in $75 \%$ yield. The molecular movement of free bpe molecules was tested by conducting the photoreaction in ground sample and heated sample of single crystals. The photoreactivity study of $\mathbf{1}$ indicates that the free bpe molecules are locked between the cationic $\left[\left\{\mathrm{Zn}\left(\mathrm{H}_{2} \mathrm{O}\right)_{3}(\text { bpe })_{2}\right\}_{2}(\mathrm{bpe})\right]^{4+}$ layers.
\end{abstract}

Keywords. Hydrogen-bonded metal complex; solid-state photoreaction; topochemical reaction; 4,4'-bipyridylethylene.

\section{Introduction}

Supramolecular structural transformation in crystals triggered by physical stimuli such as light, heat and small molecules is an emerging field in crystal engineering. ${ }^{1}$ Photoreactive olefinic double bonds have been successfully aligned to satisfy the Schmidt's geometric criteria for photoreactivity in the solid state via hydrogen bonding, halogen bonding, coordination bonding, both hydrogen and coordination bonding in discrete and infinite molecular assemblies. ${ }^{1-6}$ Despite the well-documented use of directional hydrogen bonding in bringing two $\mathrm{C}=\mathrm{C}$ bonds closer for the photochemical reactions, this strategy was rarely used in the inorganic hydrogen-bonded complexes with ligands containing $\mathrm{C}=\mathrm{C}$ bonds. ${ }^{6}$ The topochemical approach requires minimal atomic and molecular movements in the solid-state reactions. ${ }^{7}$ However, quantitative yield of products in several solid-state reactions, including [2+2] photocycloadditions, cannot be explained based on topochemical postulate. Such reactions require large molecular/ atomic motions in the solid state lattice. ${ }^{5,6,8-11}$ External forces such as light irradiation or mechanical motion induce molecular motion in the crystal lattice. For example, Kaupp and co-workers found the evidence of mechanically induced molecular migrations in the surface of solids by AFM technique. ${ }^{9}$ Large pedal-like motions of double bonds in solids prior to dimerization were observed. ${ }^{10}$ Presence of large void volume or empty channel in loosely packed crystals with weak hydrogen bonds are able to stimulate molecular movements in solid state. ${ }^{8,11}$ The molecules are able to migrate easily if they are not interlocked inside the crystal packing.

While exploring the coordination behavior of 4,4'bipyridylethylene (bpe), it was encountered that the double bonds in six bpe molecules were aligned closely around $4.0 \AA$ in parallel orientations. A 2D hydrogenbonded dinuclear complex, $\left[\left\{\mathrm{Zn}\left(\mathrm{H}_{2} \mathrm{O}\right)_{3}(\text { bpe })_{2}\right\}_{2}\right.$ (bpe $\left.)\right]$ $\left(\mathrm{NO}_{3}\right)_{4} \cdot 3$ bpe $\cdot 14 \mathrm{H}_{2} \mathrm{O},{ }^{12} \mathbf{1}$ (where bpe $=4,4^{\prime}$-bipyridylethylene) containing coordination complex cations, $\left[\left\{\mathrm{Zn}\left(\mathrm{H}_{2} \mathrm{O}\right)_{3}(\mathrm{bpe})_{2}\right\}_{2}(\mu \text {-bpe })\right]^{4+}$, free bpe molecules and lattice water molecules show a face-to-face, $\pi \cdots \pi$ stacking [3.472(2) $\AA$ and 3.735(4) $\AA$ ] of two of the four free bpe molecules with coordinated bpe ligands. Out of the eight bpe molecules, six are aligned in parallel fashion with short C . . C distances of 3.663-3.814 which are expected to undergo photoreaction. When the single crystals of $\mathbf{1}$ were subjected to UV irradiation for $4 \mathrm{~h}$ rctt-tetrakis(4-pyridyl)cyclobutane (rctttpcb isomer) was obtained in $40 \%$ yield, and further irradiation for $25 \mathrm{~h}$ produced $60 \%$ yield with disintegration of single crystals to powder. However, photoirradiation for $25 \mathrm{~h}$ of the sample ground for $5 \mathrm{~min}$ 
produced $75.8 \%$ yield. Although grinding increases the photoreactivity as compared to the reactivity of single crystal, it is not able to bring the free bpe molecules closer to the bridged or coordinated bpe by rotation and molecular movements. This may be due to the fact that the free bpe molecule is locked between the cationic $\left[\left\{\mathrm{Zn}\left(\mathrm{H}_{2} \mathrm{O}\right)_{3}(\mathrm{bpe})_{2}\right\}_{2}(\mathrm{bpe})\right]^{4+}$ layers. Hence, there is no room provided for such molecular movement.

\section{Experimental}

\subsection{Materials and Methods}

All the chemicals were used as received without further purification. All solvents used were of reagent grade. Yield of the metal complexes are reported with respect to the metal salts. The UV irradiation experiments were conducted using Luzchem photoreactor. In a typical experiment 1 ( $c a .10 \mathrm{mg}$ ) was packed between two Pyrex glass slides and irradiated ( $8 \mathrm{~W}$ dark blue phosphor lamps, measured intensity $c a .1 .75 \mathrm{~mW} \mathrm{~cm}^{-2}$ ) at $350 \mathrm{~nm}$. The FTIR spectra (KBr pellet) of all the compounds were recorded on a Bio-Rad FTIR spectrophotometer. The ${ }^{1} \mathrm{H}$ and ${ }^{13} \mathrm{C}$ NMR spectra were recorded with a Bruker ACF 300 FT-NMR spectrometer with TMS as internal reference. The yields observed on UV irradiation are reported in terms of the product distribution, obtained by integrating ${ }^{1} \mathrm{H}$ NMR spectra of the compounds. The grinding experiments were conducted manually using agate pestle and mortar. Thermogravimetric analysis of metal complexes was run on a TA Instrument SDT 2960 TGA Thermal Analyzer. The samples of $\mathbf{1}$ were ground immediately before the experiment to reduce exposure to moisture. Approximately $5 \mathrm{mg}$ of the sample was used for each experiment. Samples were heated at a constant rate of $5^{\circ} \mathrm{C} \cdot \mathrm{min}^{-1}$ from room temperature to $600^{\circ} \mathrm{C}$ and the samples held in a continuous flow nitrogen atmosphere $(100 \mathrm{~mL} / \mathrm{min})$. SEM images were recorded on a JOEL JSMT220A Scanning Microscopy, with the accelerating voltage of $10 \mathrm{KV}$. The samples were smeared over a double-sided adhesive tape placed over an aluminum stub.

\subsection{Synthesis of Complexes}

2.2a $\left[\left\{\mathrm{Zn}\left(\mathrm{H}_{2} \mathrm{O}\right)_{3}(\text { bpe })_{2}\right\}_{2}(\right.$ bpe $\left.)\right]\left(\mathrm{NO}_{3}\right)_{4} \cdot 3$ bpe $\cdot 14 \mathrm{H}_{2} \mathrm{O}$

(1): Single crystals of $\mathbf{1}$ were synthesized based on the reported procedure with a slight modification. ${ }^{12}$ $\mathrm{Zn}\left(\mathrm{NO}_{3}\right)_{2} 6 \mathrm{H}_{2} \mathrm{O} \quad(14 \mathrm{mg}, 0.05 \mathrm{mmol})$ was dissolved in $0.3 \mathrm{~mL}$ of $\mathrm{H}_{2} \mathrm{O}$ and carefully layered with $0.3 \mathrm{~mL}$ acetone solution of bpe $(18 \mathrm{mg}, 0.1 \mathrm{mmol})$. Colorless block crystals were formed after three days, which were decanted and dried in air. [Yield: $0.068 \mathrm{~g}, 57 \%$ ]. Elemental analysis, Calcd. for $\mathrm{C}_{108} \mathrm{H}_{130} \mathrm{~N}_{22} \mathrm{O}_{32} \mathrm{Zn}_{2}$ (2379.08): C, 54.52; H, 5.52; N, 12.96\%. Found: C, $54.71 ; \mathrm{H}, 5.78 ; \mathrm{N}, 12.85 \%$. IR/ $\mathrm{cm}^{-1}: 1606 \mathrm{~s}, 1560 \mathrm{~m}$, $1502 \mathrm{~m}, 1484 \mathrm{~s}, 1423 \mathrm{~s}, 1291 \mathrm{w}, 1071 \mathrm{~s}, 1026 \mathrm{~s}, 825 \mathrm{~s}$, 549s. ${ }^{1} \mathrm{H}$ NMR (DMSO- $\left.d_{6}, 300 \mathrm{MHz}\right): \delta_{\mathrm{H}} 8.61(\mathrm{~d}, 4 \mathrm{H}$, $\delta$-pyridyl proton), 7.63 (d, 4H, $\delta$-pyridyl proton), 7.56 (s, $2 \mathrm{H}, \mathrm{CH}=\mathrm{CH}) .{ }^{13} \mathrm{C} \mathrm{NMR}\left(\mathrm{DMSO}-d_{6}, 300 \mathrm{MHz}\right): \delta_{\mathrm{c}}$ 150.52 ( $\delta$-pyridyl carbon), 144.97 ( $\delta$-pyridyl carbon), $130.99(\mathrm{C}=\mathrm{C}), 121.80$ ( $\delta$-pyridyl carbon).

\subsection{UV Irradiation of 1}

Single crystals, dehydrated crystals, and manually powdered samples in a pestle and mortar for 5 and $20 \mathrm{~min}$ were exposed to UV light for 1,4 and $25 \mathrm{~h} .{ }^{1} \mathrm{H}$ NMR $\left(\mathrm{DMSO}-d_{6}, 300 \mathrm{MHz}\right) \delta=8.33(\mathrm{~d}, 4 \mathrm{H}, \delta$-pyridyl proton), 7.22(d, $4 \mathrm{H}, \delta$-pyridyl proton), $4.65(\mathrm{~s}, 4 \mathrm{H}$, $\mathrm{CH}-\mathrm{CH}$ ), ${ }^{13} \mathrm{C}$ NMR (DMSO-d $\left.6,300 \mathrm{MHz}\right) 149.54$ ( $\delta$-pyridyl carbon), 123.68 ( $\delta$-pyridyl carbon $), 44.74(\mathrm{CH}$ $\mathrm{CH}) . \mathrm{IR} / \mathrm{cm}^{-1}: 3389 \mathrm{~m}, 3054 \mathrm{w}, 2375 \mathrm{w}, 1603 \mathrm{~m}, 1500 \mathrm{w}$, 1382s, 1234w, 1012w, 823m, 552m.

\subsection{NMR studies of 1}

The product distributions of photochemical [2+2] cycloaddition reaction of $\mathbf{1}$ under various experimental conditions are shown in Table S1 (Supplementary Information). The percentage of the products was calculated as the ratio of all the reactant peaks to the product peaks. The values were obtained by integrating the intensities of two doublets and singlet peaks for each set of bpe and products, and averaged.

\section{Results and Discussion}

Although similar reactants and ratio were used to synthesize $\left[\mathrm{Zn}(\mathrm{bpe})_{2}\left(\mathrm{H}_{2} \mathrm{O}\right)_{4}\right]\left(\mathrm{NO}_{3}\right)_{2} \cdot 8 / 3 \quad \mathrm{H}_{2} \mathrm{O} \cdot 2 / 3$ bpe $^{6 \mathrm{a}}$ and $\mathbf{1}$, the effect of different solvent combinations and the reaction conditions produced two different hydrogen-bonded Zn(II) complexes. Lee and coworkers described the structure of this compound. ${ }^{12}$ The compound $\mathbf{1}$ is a dinuclear $\mathrm{Zn}(\mathrm{II})$ coordination complex (Figure 1) containing $\left[\left\{\mathrm{Zn}\left(\mathrm{H}_{2} \mathrm{O}\right)_{3}(\text { bpe })_{2}\right\}_{2}(\mu \text {-bpe })\right]^{4+}$ cation with free bpe and lattice water molecules. The complex forms a $H$-shaped dinuclear $\mathrm{Zn}$ (II) complex via bridging of the bpe spacer ligand at the centre using T- shaped metal geometries as shown in Figure 1.

Out of eight bpe molecules, five are coordinated and three are free bpe in the crystal lattice. In 1, all 


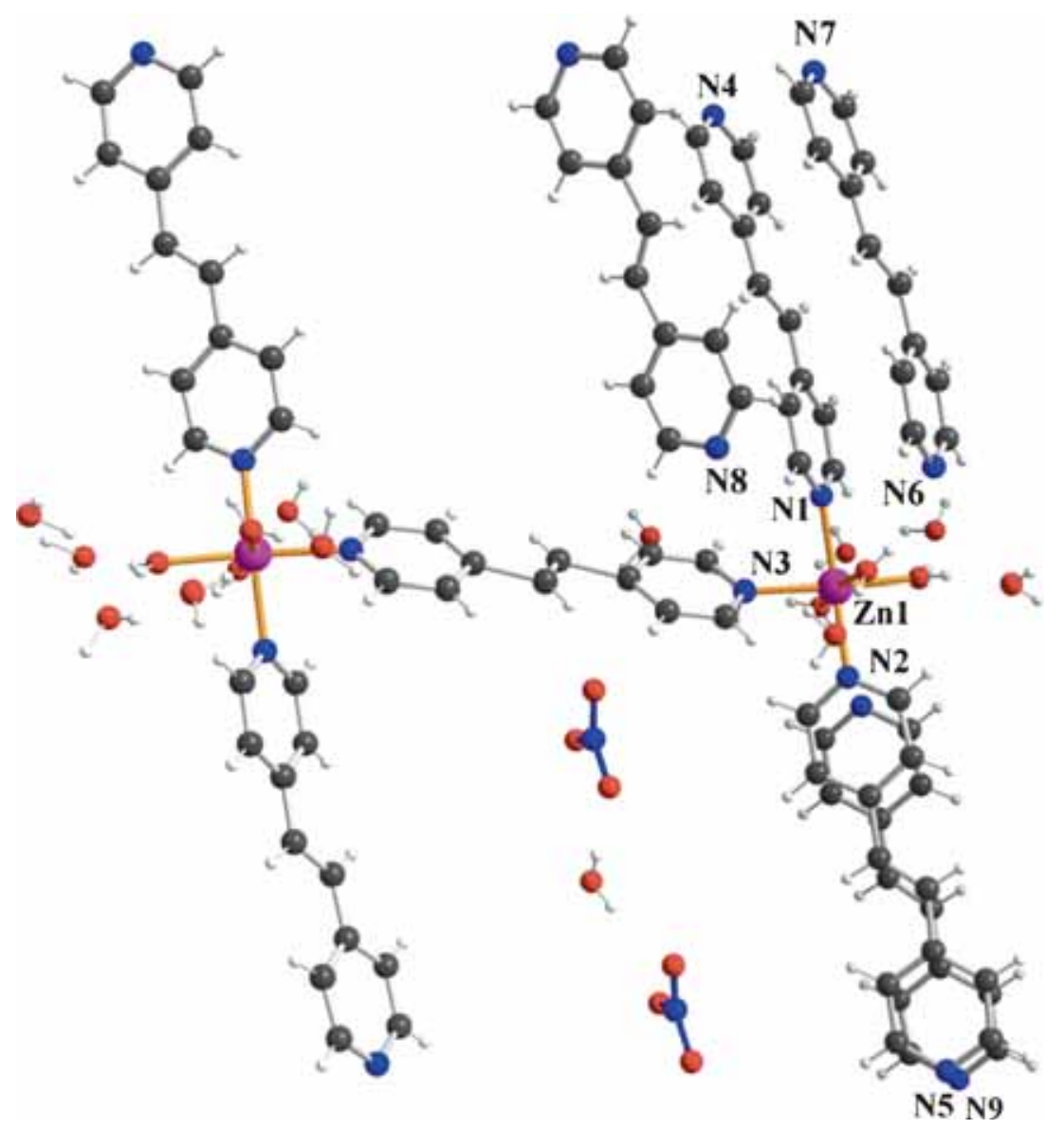

Figure 1. A perspective view of the fundamental unit in 1. Only relevant atoms are assigned.

the bpe molecules are aligned along $b$-axis except one that bridges two metal ions. Hence, all the bpe ligands except the bridged one, are left with an imine $\mathrm{N}$ atom uncoordinated. This uncoordinated $\mathrm{N}$ atom of bpe molecules in $\mathbf{1}$ form hydrogen bonding via $\mathrm{O}-\mathrm{H} \cdots \mathrm{N}$ interactions with the neighboring aqua ligands and lattice water molecules. The $\mathrm{O}-\mathrm{H} \cdots \mathrm{N}$ hydrogen bond distance and angles are given in Table S2 (Supplementary Information). As a result, the $H$-shaped cations form a 2D hydrogen-bonded structure. The 2D hydrogen bonded polymer propagates along the (01-1) plane. Two of the four free bpe molecules show a face-toface $\pi \cdots \pi$ stacking [3.472(2) $\AA$ and 3.735(4) $\AA$ ] with coordinated bpe ligands.

There are three coordinated aqua ligands and seven lattice water molecules in the asymmetric unit and they form hydrogen bonding via $\mathrm{O}-\mathrm{H} \cdots \mathrm{O}$ interactions. The water molecules in the crystal lattice form two discrete water clusters, namely, $\left(\mathrm{H}_{2} \mathrm{O}\right)_{6}$ and $\left(\mathrm{H}_{2} \mathrm{O}\right)_{4}$ based on cyclohexane chair and cyclobutane structures, respectively. The $\mathrm{N}$-atoms of the fourth free lattice bpe molecule are hydrogen-bonded via $\mathrm{O}-\mathrm{H} \cdots \mathrm{N}$ interactions with one of the hydrogen atoms of the neighboring $\left(\mathrm{H}_{2} \mathrm{O}\right)_{4}$ tetramer.
Ramamurthy and Venkatesan described minimum translational molecular movement in crystals based on topochemical photodimerization of coumarin derivative. ${ }^{13}$ In addition to the minimum distance (d) between the $\mathrm{C}=\mathrm{C}$ bonds, the authors used geometrical parameters $\theta_{1}, \theta_{2}$ and $\theta_{3}$ to compare the photo reactivity of coumarin in solid state as shown in Figure 2. Here, $\theta_{1}$ represents rotational angle of one double bond with respect to other, $\theta_{2}$ represents obtuse angle of the parallelogram formed by double bonds $\mathrm{C}_{3}, \mathrm{C}_{4}, \mathrm{C}_{3}^{\prime}$ and $\mathrm{C}_{4}^{\prime}$ and $\theta_{3}$ represents angle between least square plane through the reactive bonds $\mathrm{C}_{3}, \mathrm{C}_{4}, \mathrm{C}_{3}^{\prime}$ and $\mathrm{C}_{4}^{\prime}$ and that passing through $\mathrm{C}_{2}^{\prime}, \mathrm{C}_{3}, \mathrm{C}_{4}$ and $\mathrm{C}_{10}^{\prime}$. The ideal values for the angle $\theta_{1}, \theta_{2}$ and $\theta_{3}$ between the reactive $\mathrm{C}=\mathrm{C}$ bonds are 0,90 and $90^{\circ}$. A similar methodology was employed in the $\mathrm{C}=\mathrm{C}$ alignment in bpe ligands of the hydrogen-bonded metal complexes as shown in Figure 3.

Out of the eight bpe, six are aligned in parallel fashion in 1 with short C...C distances of 3.663$3.814 \AA$ and these are expected to undergo photoreaction (Figure 4). The centroid distances of the double bonds and $\theta_{1}, \theta_{2}$ and $\theta_{3}$ for $\mathbf{1}$ are shown in Table 1. 

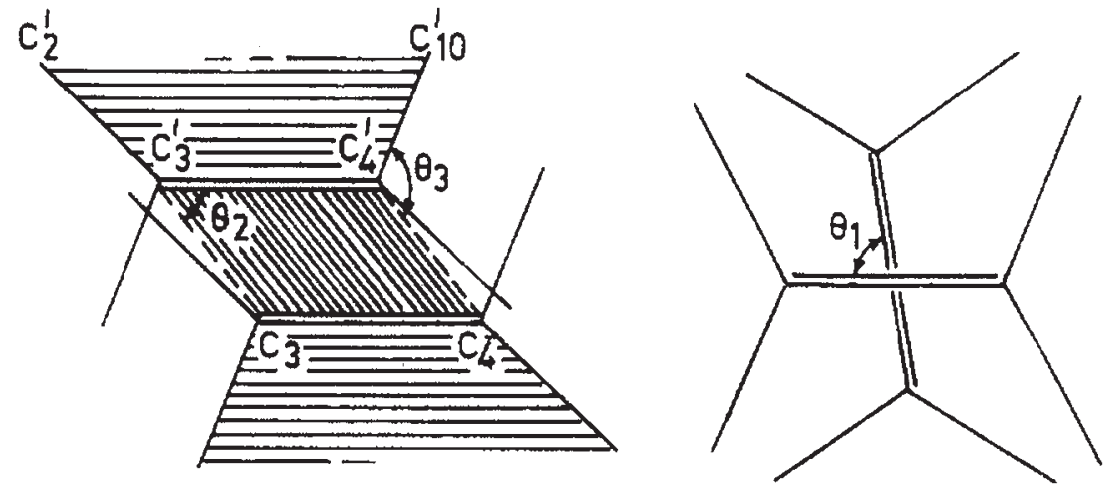

Figure 2. Geometrical parameters used in the relative representation of the reactant double bonds in coumarin. Reprinted (adapted) with permission from Ramamurthy V and Venkatesan K 1987 Chem. Rev. 87 433. Copyright (1987), American Chemical Society.

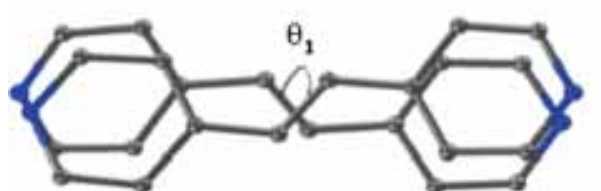

(a)

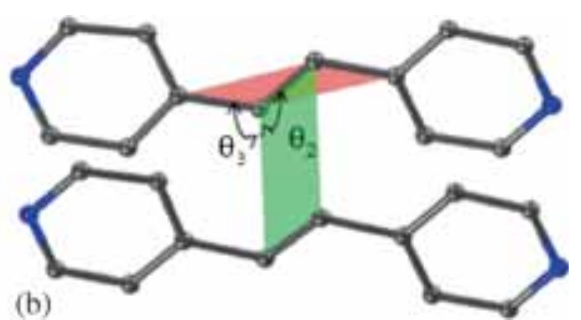

(b)

Figure 3. Geometrical parameters used in the relative representation of $\mathrm{C}=\mathrm{C}$ double bonds in bpe: (a) shows $\theta_{1}$ and (b) shows $\theta_{2}$ and $\theta_{3}$ (averaged).

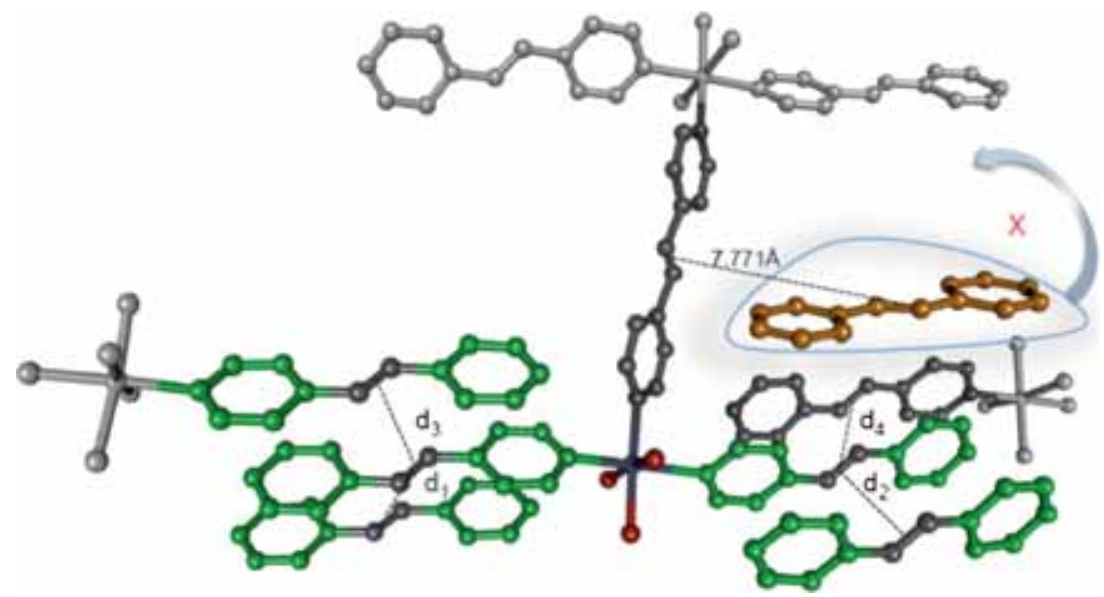

Figure 4. A perspective view of the packing arrangement of $\mathbf{1}$ (green color indicates $\pi \cdots \pi$ stacking between the pyridyl rings containing $\mathrm{C}=\mathrm{C}$ distances $\mathrm{d}_{1}$ and $\mathrm{d}_{2}$, orange color indicates the photostable free bpe molecule).

Table 1. The parameters $\theta_{1}, \theta_{2}$ and $\theta_{3}$ in degrees $\left(^{\circ}\right)$ are various angles between the reactive double bonds within the assembly and orientation of the reactive double bonds in $\mathbf{1}$.

\begin{tabular}{lcccc}
\hline $\begin{array}{l}\text { Distances between the } \\
\text { nearest reactive } \mathrm{C}=\mathrm{C}, \AA\end{array}$ & $\theta_{1}$ & $\theta_{2}$ & $\theta_{3}$ & $\begin{array}{c}\text { Alignment fashion of } \\
\text { reactive } \mathrm{C}=\mathrm{C} \text { bonds }\end{array}$ \\
\hline $\mathrm{d}_{1}: 3.747$ & 2 & 90 & 64 & parallel \\
$\mathrm{d}_{2}: 3.814$ & 0 & 89 & 73 & parallel \\
$\mathrm{d}_{3}: 3.663$ & 0 & 90 & 67 & parallel \\
$\mathrm{d}_{4}: 4.383$ & 0 & 89 & 62 & parallel \\
\hline
\end{tabular}


The two free bpe molecules pair up well in parallel fashion via $\pi \cdots \pi$ stacking with the adjacent bpe ligands $\left(\mathrm{d}_{1}=3.747 \AA\right.$ and $\left.\mathrm{d}_{2}=3.814 \AA\right)$. The two coordinated bpe molecules from two $H$-complex interact through $\pi \cdots \pi$ stacking $(3.708 \AA$ ) resulting in the alignment of the olefins in a distance $\mathrm{d}_{3}(3.663 \AA)$ along $\mathrm{d}_{1}$. However, an offset-arrangement of two $H$-type along $\mathrm{d}_{2}$ results in the alignment of two olefins in parallel, but distance greater than $4.2 \AA(4.383 \AA) .{ }^{7}$ Hence, there are three pairs of potentially reactive olefins from six bpe molecules.

The bpe ligand which acts as a bridge between the two $\mathrm{Zn}$ (II) atoms is expected to be photo-stable. However, the free bpe molecule inside the lattice, left alone in off-stack arrangement with nearest coordinated bpe, in principle can undergo rotation or molecular movement to facilitate a $\mathrm{C}=\mathrm{C}$ pair alignment. The minimum distance between this free lattice bpe molecule and the nearest coordinated bpe ligand is $5.174 \AA$. However, this coordinated bpe ligand is paired with another free

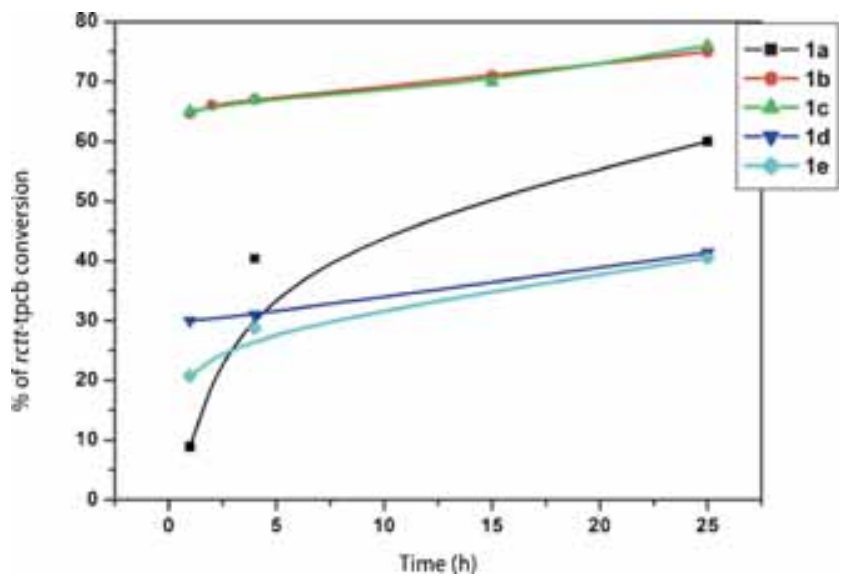

Figure 5. Plots showing the progress of photoconversion of 1 over various time intervals to rctt-tpcb isomer as monitored by ${ }^{1} \mathrm{H}$ NMR in DMSO- $d_{6}$. 1a: single crystal, 1b: single crystal ground for $5 \mathrm{~min}$, 1c: single crystal ground for $20 \mathrm{~min}$, 1d: single crystal heated at $60^{\circ} \mathrm{C}$ and 1e: single crystal heated at $100^{\circ} \mathrm{C}$. bpe via $\pi \cdots \pi$ stacking $\left(\mathrm{d}_{2}\right)$. Hence, the free bpe has to undergo either rotation or molecular motion along the bridged bpe ligand in a distance of $7.771 \AA$. This could only be possible if there is enough space between the $H$-shaped metal complex in the medium having water molecules and nitrate anions.

We have investigated the photoreactivity of $\mathbf{1}$ in the solid-state. When the single crystals of $\mathbf{1}$ were subjected to UV irradiation for $4 \mathrm{~h}, r c t$-tpcb isomer was obtained in $40 \%$ yield, and further irradiation for $25 \mathrm{~h}$ produced $60 \%$ yield with disintegration of single crystals to powder as monitored by ${ }^{1} \mathrm{H}-\mathrm{NMR}$ in DMSO- $d_{6}$. To test whether free bpe molecules undergo molecular motion inside the crystal lattice, the photoreaction was conducted for ground and heated samples of single crystals. The plots in Figure 5 show the percentage of conversion for $r c t t$-tpcb versus time for $\mathbf{1}$ under various conditions.

A $25 \mathrm{~h}$ photo-irradiation of sample ground for $5 \mathrm{~min}$ produced $75.8 \%$ rctt-tpcb as indicated by ${ }^{1} \mathrm{H}$ NMR spectrum in DMSO- $d_{6}$ (Figure 6). In other words, six bpe molecules underwent photoreaction after grinding. The photoreactivity of $\mathbf{1}$ is shown in Scheme 1 . Although the bpe pairs oriented with $d_{3}$ distance is the least, the packing arrangement and orientations (Figure 4) indicate that the bpe molecules aligned with $\mathrm{d}_{1}$ and $\mathrm{d}_{2}$ underwent photoreaction. The reason being that the free bpe molecules can be moved easily via breaking of the weak hydrogen boning interaction. ${ }^{14}$ Although the pyridyl groups are aligned in parallel fashion $\left(\mathrm{d}_{3}\right)$ between the coordinated bpe molecules, molecular movements are restricted between these coordinated ligands. If the pairs between $\mathrm{d}_{3}$ react, we can only expect the conversion of $c a$. $50 \%$ since the two free bpe molecules are left unreacted.

Grinding for $20 \mathrm{~min}$ can produce larger surface area than grinding for $5 \mathrm{~min}$. However, the reaction progress indicates there is not much increase in the reactivity due to longer grinding time implying that the surface area

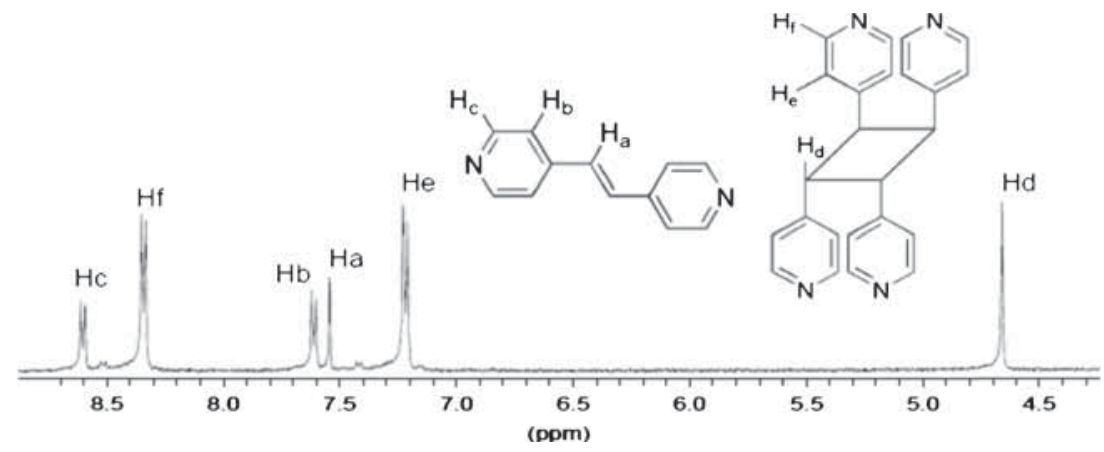

Figure 6. ${ }^{1} \mathrm{H}$ NMR spectrum of $\mathbf{1}$ (sample of single crystal ground for $5 \mathrm{~min}$ ) after $25 \mathrm{~h}$ UV irradiation (rctt-tpcb: $75 \%$ ) in DMSO- $d_{6}$. 

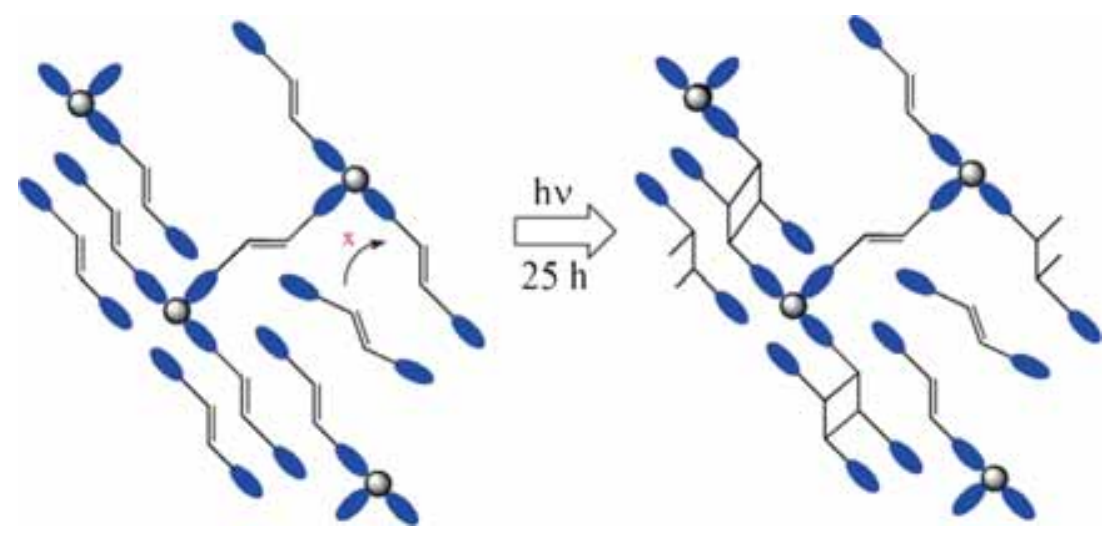

Scheme 1. The schematic representation of the photoreactivity of $\mathbf{1}$.

is not responsible for increase in reactivity. Although grinding increases the reactivity as compared to the reactivity of single crystal, it is not able to bring the free bpe molecules closer to the bridged, coordinated bpe by rotation and molecular movements. This may be due to the fact that the free bpe molecule is locked between the cationic $\left[\left\{\mathrm{Zn}\left(\mathrm{H}_{2} \mathrm{O}\right)_{3}(\text { bpe })_{2}\right\}_{2}\right.$ (bpe $\left.)\right]^{4+}$ layers, as shown in Figure 7. Hence, there is no room for such molecular movement. ${ }^{8,11}$ However, the reactivity occurred in the case of $\left[\mathrm{Zn}(\mathrm{bpe})_{2}\left(\mathrm{H}_{2} \mathrm{O}\right)_{4}\right]\left(\mathrm{NO}_{3}\right)_{2} \cdot 8 / 3$ $\mathrm{H}_{2} \mathrm{O} \cdot 2 / 3$ bpe $^{6 \mathrm{a}}$ via the bpe ligands with antiparallel $\mathrm{C}=\mathrm{C}$ bonds which undergo pedal-like motion prior to photodimerization. Grinding single crystals into powder in the latter case accelerates the pedal motion of antiparallel $\mathrm{C}=\mathrm{C}$ bonds into parallel alignment as well as facilitates the motion of free bpe in solid.

The influence of water molecules on the photoreactivity was also investigated using TGA experiments (Figure 8 and Table 2). The decomposition temperature for lattice water molecules is in the range of $50-70^{\circ} \mathrm{C}$ and the coordinated water molecule is at $100^{\circ} \mathrm{C}$. Based on this observation, the photoreactivity was monitored

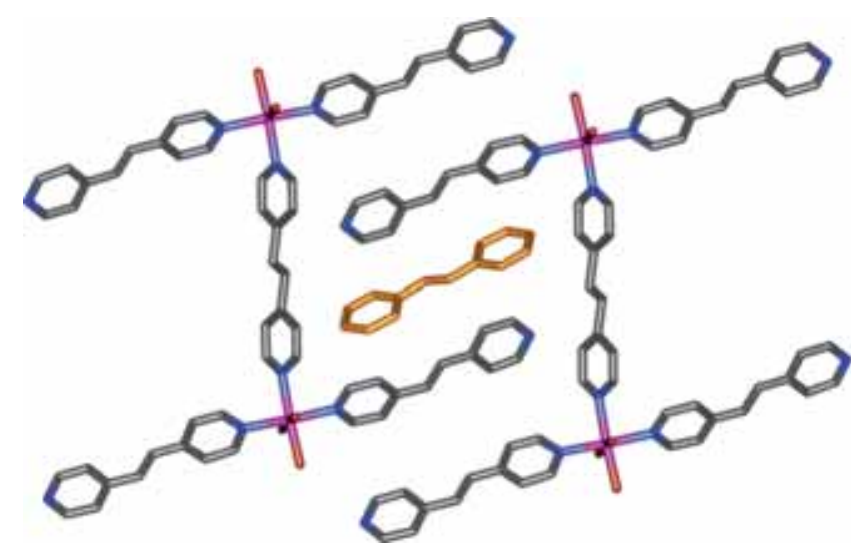

Figure 7. A perspective view of $\mathbf{1}$ in which the free bpe molecule (orange color) is locked between the two cationic layers. for the single crystals were heated to $60^{\circ} \mathrm{C}$ and $100^{\circ} \mathrm{C}$. A slight increase in photoreactivity was observed for crystals heated at $60^{\circ} \mathrm{C}$ after $1 \mathrm{~h}$ irradiation. But there is no difference between the photoreactivity of the crystals heated at $60^{\circ} \mathrm{C}$ and $100^{\circ} \mathrm{C}$ for $25 \mathrm{~h}$ irradiation. The percentage water loss due to grinding is similar for samples ground for $5 \mathrm{~min}$ and $20 \mathrm{~min}$. If the water loss is responsible, then the single crystals heated to $60^{\circ} \mathrm{C}$

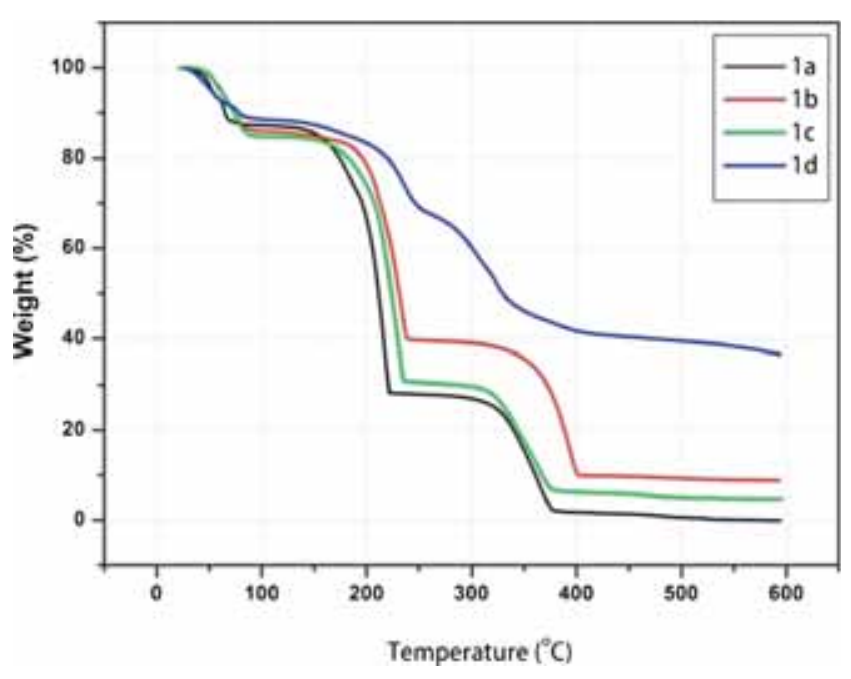

Figure 8. TGA of 1. Before UV irradiation (1a: single crystal, 1b: single crystal ground for $5 \mathrm{~min}, \mathbf{1 c}$ : single crystal ground for $20 \mathrm{~min}$ ). TGA after $25 \mathrm{~h} \mathrm{UV}$ irradiation (1d: single crystal ground for $20 \mathrm{~min}$ ).

Table 2. \% Weight loss of $\mathrm{H}_{2} \mathrm{O}$ molecules in $\mathbf{1}$ from TGA.

Compound $\mathbf{1}^{*}$ $\%$ Wt. loss

Single crystals

15.34

Crystals ground for $5 \mathrm{~min}$

Crystals ground $20 \mathrm{~min}$ ground

Crystals ground $20 \mathrm{~min}$ (after 25h UV)

11.34

*Expected Weight loss for $20 \mathrm{H}_{2} \mathrm{O}$ molecules is $15.13 \%$ 

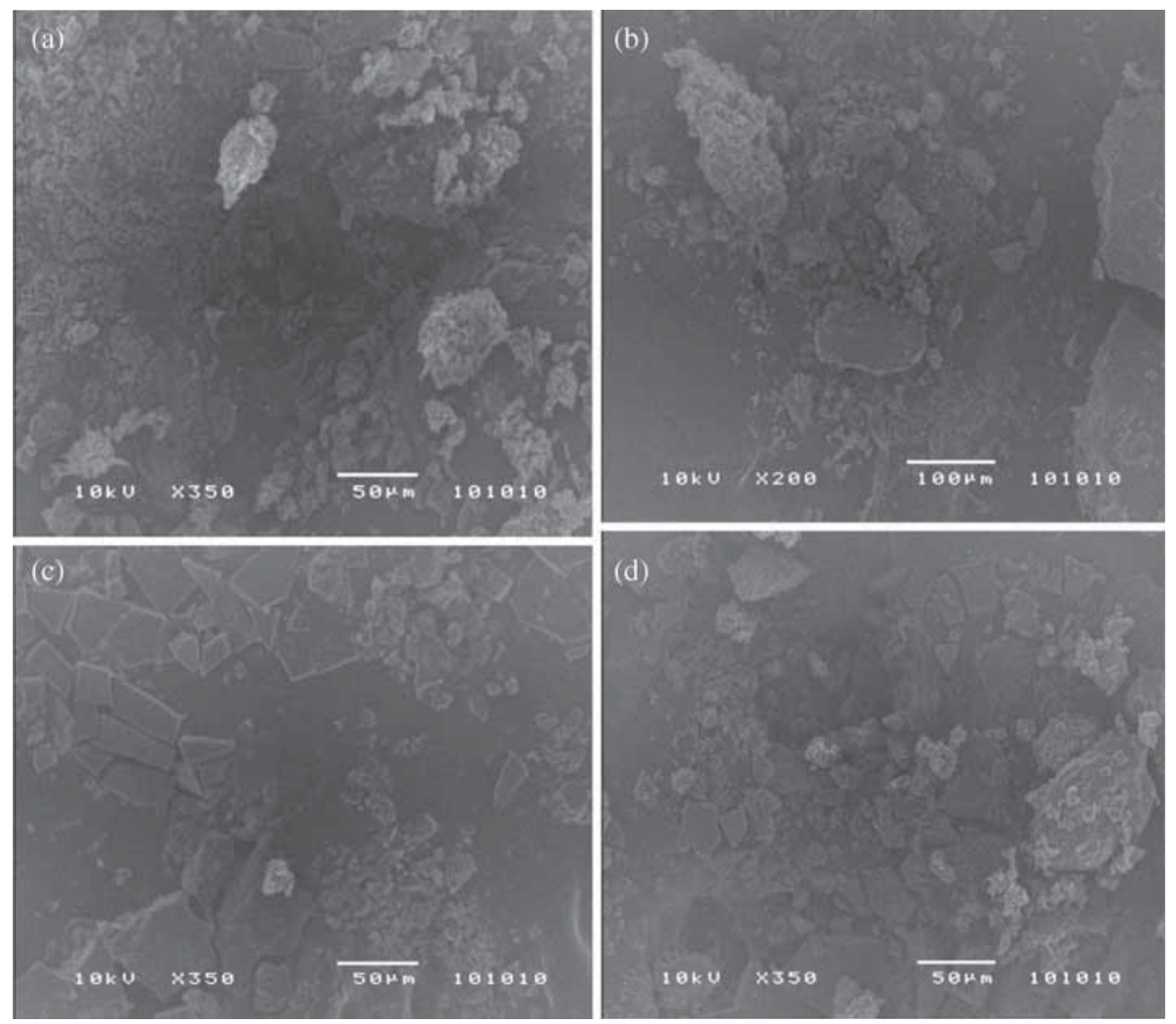

Figure 9. SEM images of $\left[\mathrm{Zn}(\mathrm{bpe})_{2}\left(\mathrm{H}_{2} \mathrm{O}\right)_{4}\right]\left(\mathrm{NO}_{3}\right)_{2} \cdot 8 / 3 \mathrm{H}_{2} \mathrm{O} \cdot 2 / 3$ bpe. (a) Powder sample, (b) single crystals ground for $5 \mathrm{~min}$, (c) single crystals ground for $20 \mathrm{~min}$, and (c) SEM images of $\mathbf{1}$, sample ground for $5 \mathrm{~min}$.

and $100^{\circ} \mathrm{C}$ should have shown higher reactivity than other samples. ${ }^{6 a}$ The loss of water molecules in the heated crystals cause the breaking of $\mathrm{O}-\mathrm{H}$. . O hydrogen bonding interactions in the solid which may result in the off-stacking of bpe molecules and hence less photoreactive. Only the bpe pairs indicated as $d_{3}$ are likely to react after the water loss.

Mechanical grinding, milling or kneading of two or more reactants have produced novel molecular compounds, and solvent-free green chemical routes to supramolecular aggregates, co-crystals and coordination networks. ${ }^{15}$ These mechanical methods are known to accelerate the reactivity due to increase in the surface area and formation of various defects in the crystals. ${ }^{16}$ The reactivity activated mechanochemically within a crystal lattice is thought to take place in a constrained environment generated by the surrounding molecules. One may argue that increase in surface area in $\left[\mathrm{Zn}(\mathrm{bpe})_{2}\left(\mathrm{H}_{2} \mathrm{O}\right)_{4}\right]\left(\mathrm{NO}_{3}\right)_{2} \cdot 8 / 3 \mathrm{H}_{2} \mathrm{O} \cdot 2 / 3$ bpe during grinding may in fact, increase the photoreactivity. To answer this question, we have used microscopic and SEM images of the ground single crystals and bulk samples of $\left[\mathrm{Zn}(\mathrm{bpe})_{2}\left(\mathrm{H}_{2} \mathrm{O}\right)_{4}\right]\left(\mathrm{NO}_{3}\right)_{2} \cdot 8 / 3 \mathrm{H}_{2} \mathrm{O} \cdot 2 / 3$ bpe. The SEM images (Figure 9) show that there is not much difference between these two samples. Although sample ground for $20 \mathrm{~min}$ shows plate-like morphology, the surface area has not increased from sample ground for $5 \mathrm{~min}$ and bulk sample. Therefore, it is likely that the molecular motion which occurred in $\left[\mathrm{Zn}(\text { bpe })_{2}\left(\mathrm{H}_{2} \mathrm{O}\right)_{4}\right]$ $\left(\mathrm{NO}_{3}\right)_{2} \cdot 8 / 3 \mathrm{H}_{2} \mathrm{O} \cdot 2 / 3$ bpe is due to mechanical force (grinding), and not due to increase in the surface area. Mechanical grinding accelerates the pedal motion as well as the movements of free bpe molecules in $\left[\mathrm{Zn}(\mathrm{bpe})_{2}\left(\mathrm{H}_{2} \mathrm{O}\right)_{4}\right]\left(\mathrm{NO}_{3}\right)_{2} \cdot 8 / 3 \mathrm{H}_{2} \mathrm{O} \cdot 2 / 3$ bpe, but the same grinding only just increases the photoreactivity in 1. It also noted that these compounds appear to remain as single phase during the mechanical grinding.

\section{Conclusions}

Hydrogen-bonded metal coordination complexes have been employed to align the $\mathrm{C}=\mathrm{C}$ bonds in bpe for $[2+2]$ cycloaddition reactions. Photoreactivity of solids containing more than one pair of well-aligned $\mathrm{C}=\mathrm{C}$ bonds are rarely studied. Here, it appears to be six olefins in a row which satisfy the Schmidt distance criterion with parallel orientation. These six are aligned in parallel fashion with short C. . C distances of 3.663$3.814 \AA$ and they are expected to undergo photoreaction. When the single crystals were subjected to 
$\mathrm{UV}$ irradiation for $4 \mathrm{~h}$ rctt-tpcb isomer was obtained in $40 \%$ yield, and further irradiation for $25 \mathrm{~h}$ produced $60 \%$ yield with disintegration of single crystals to powder. However, irradiation of sample ground for 5 min for $25 \mathrm{~h}$ produced $75.8 \%$ yield. Although grinding increases the photoreactivity as compared to the reactivity of single crystal, it is not able to bring the free bpe molecules closer to the bridged or coordinated bpe by rotation and molecular movements. This may be due to the fact that the free bpe molecule is locked between the cationic $\left[\left\{\mathrm{Zn}\left(\mathrm{H}_{2} \mathrm{O}\right)_{3}(\mathrm{bpe})_{2}\right\}_{2}(\mathrm{bpe})\right]^{4+}$ layers. Hence, there is no room for such molecular movement. Mechanical motion in the crystal may also facilitate the movements of molecules to align in parallel, as required for photodimerization reaction. An internal pressure is exerted on the molecules by mechanical motion in the free volume between the cationic layers. However, such a large motion does not occur in the crystal lattice if there is not enough space or free volume in the surrounding. The movements are also not facilitated if the free bpe molecules are interlocked between the cationic layers. As we observed earlier, the molecules can be moved easily only if they are loosely packed inside the crystal lattice.

\section{Supplementary Information (SI)}

All additional information pertaining to the characterization of photoreacted $\mathbf{1}$ under various conditions using ${ }^{1} \mathrm{H}$ NMR, product distribution, TGA, and crystallographic data of $\mathbf{1}$ are given in the Supporting Information available at www.ias.ac.in/chemsci.

\section{Acknowledgments}

The author would like to acknowledge the support provided by the Deanship of Scientific Research (DSR) at King Fahd University of Petroleum \& Minerals (KFUPM) for funding this work through project No. IN131005. The author is grateful to Prof. Jagadese J. Vittal, National University of Singapore for helpful discussion on the manuscript.

\section{References}

1. (a) Vittal J J 2007 Supramolecular structural transformations involving coordination polymers in the solid state Coord. Chem. Rev. 251 1781; (b) Medishetty R and Vittal J J 2014 Metal-Organic Frameworks for Photochemical Reactions Struct. Bond. 157105

2. MacGillivray L R, Papaefstathiou G S, Friščić $T$, Hamilton T D, Bučar D-K, Chu Q, Varshney D B and Georgiev I G 2008 Supramolecular control of reactivity in the solid state: From templates to ladderanes to metal-organic frameworks Acc. Chem. Res. 41280

3. Sinnwell M A, Ingenthron B J, Groeneman R H and MacGillivray L R 2016 Stereoselective and Quantitative [2+2] Photodimerization of a Symmetrical Octafluoro Stilbene in the Solid State: Face-to-Face Stacking of the Fluorinated Rings in trans-1,2bis(2,3,5,6-tetrafluorophenyl)ethylene J. Fluor. Chem. 1885

4. (a) Medishetty R, Park I, Lee S S and Vittal J J 2016 Solid-state polymerisation via $[2+2]$ cycloaddition reaction involving coordination polymers Chem. Commun. 52 3989; (b) Medishetty R, Tandiana R, Wu J, Bai Z, Du Y and Vittal J J 2015 A step-by-step Assembly of a 3D Coordination Polymer in the Solid-state by Desolvation and [2+2] Cycloaddition Reactions Chem.-Eur. J. 21 11948; (c) Kole G K, Peedikakkal A M P, Toh B M F and Vittal J J 2013 Solid-State Structural Transformations and Photoreactivity of 1D-Ladder Coordination Polymers of $\mathrm{Pb}^{\mathrm{II}}$ Chem.-Eur. J. 193962

5. (a) Nagarathinam M, Peedikakkal A M P and Vittal J J 2008 Stacking of double bonds for photochemical [2+2] cycloaddition reactions in the solid-state Chem. Commun. 42 5277; (b) Kole G K and Vittal J J 2013 Solidsate Reactivity and Structural Transformations Involing Coordination Polymers Chem. Soc. Rev. 421755

6. (a) Peedikakkal A M P and Vittal J J 2008 Chem.-Eur. J. 14 5329; (b) Medishetty R, Tandiana R and Vittal J J 2014 Stepwise Host-Guest [2 + 2] Photoreaction in a Hydrogen-Bonded One-Dimensional Coordination Polymer to a Two-Dimensional Layered Structure Cryst. Growth. Des. 143186

7. (a) Schmidt G M J 1971 Photodimerization in the solidstate Pure Appl. Chem. 27 647; (b) Gautam R D and Kannan V 1986 What is the maximum yield in the solid state cinnamic aciddimerisation? A combinatorial mathematical approach J. Chem. Sci. 96 351; (c) Gopalan R S and Kulakarni G U 2001 An investigation of the photo-reactive and unreactive polymorphs of $o$-ethoxy cinnamic acid and of its photodimer J. Chem. Sci. 113 307

8. Natarajan A, Mague J T, Venkatesan K, Arai T and Ramamurthy V 2006 Volume-demanding cis-trans isomerization of 1, 2-diaryl olefins in the solid state J. Org. Chem. 711055

9. Kaup G and Naimi-Jamal M R 2005 Mechanically induced molecular migrations in molecular crystals CrystEngComm 7402

10. (a) Harada J and Ogawa K 2014 What Molecules Are Likely or Unlikely To Undergo Pedal Motions in Crystals? Cryst. Growth. Des. 14 5182; (b) Harada J and Ogawa K 2009 Pedal Motion in Crystals Chem. Soc. Rev. 38 2244; (c) Harada J and Ogawa K 2001 Invisible but Common Motion in Organic Crystals: A Pedal Motion in Stilbenes and Azobenzenes J. Am. Chem. Soc. 123 10884; (d) Chu Q, Swenson D C and MacGillivray L R 2005 A Single-Crystal-to-Single-Crystal Transformation Mediated by Argentophilic Forces Converts a Finite Metal Complex into an Infinite Coordination Network Angew. Chem. Int. Ed. 443569

11. Natarajan A, Mague $\mathrm{J}$ T, Venkatesan $\mathrm{K}$ and Ramamurthy V 2005 Large molecular motions are 
tolerated in crystals of diamine double salt of transchlorocinnamic acids with trans-1, 2-diaminocyclohexane Org. Lett. 71895

12. Lee J Y, Hong S J, Kim C and Kim Y 2005 Construction of an interpenetrated 3-D network by [2 +2$]$ cycloaddition of $\mathrm{Zn}(\mathrm{ClO} 4) 2$ and 1,2-trans-(4-pyridyl)ethene: Counter anion effects Dalton Trans. 3716

13. Ramamurthy V and Venkatesan K 1987 Photochemical reactions of organic crystals Chem. Rev. 87433
14. Sokolov A N, Swenson D C and MacGillivray L R 2008 Conformational polymorphism in a heteromolecular single crystal leads to concerted movement akin to collective rack-and-pinion gears at the molecular level Proc. Natl. Acad. Sci. USA 1051794

15. Braga D and Grepioni F 2004 Reactions between or within molecular crystals Angew. Chem. Int. Ed. $\mathbf{4 3} 4002$

16. Boldyrev V V 2004 Mechanochemical modification and synthesis of drugs J. Mater. Sci. 395117 